\title{
The Antioxidant Cofactor
} Alpha-Lipoic Acid May Control
Endogenous Formaldehyde
Metabolism in Mammals

\author{
Anastasia V. Shindyapina ${ }^{1,2}$, Tatiana V. Komarova ${ }^{1,2}$, Ekaterina V. Sheshukova ${ }^{1,2}$, \\ Natalia M. Ershova ${ }^{1,2}$, Vadim N. Tashlitsky ${ }^{3}$, Alexander V. Kurkin ${ }^{3}$, Ildar R. Yusupov ${ }^{3}$, \\ Garik V. Mkrtchyan ${ }^{2}$, Murat Y. Shagidulin ${ }^{4}$ and Yuri L. Dorokhov ${ }^{1,2 *}$

\begin{abstract}
1 Department of Genetics and Biotechnology, N. I. Vavilov Institute of General Genetics, Russian Academy of Science, Moscow, Russia, ${ }^{2}$ Department of Chemistry and Biochemistry of Nucleoproteins, A. N. Belozersky Institute of Physico-Chemical Biology, Lomonosov Moscow State University, Moscow, Russia, ${ }^{3}$ Faculty of Chemistry, Lomonosov Moscow State University, Moscow, Russia, ${ }^{4}$ Academician V. I. Schumakov Federal Research Center of Transplantology and Artificial Organs, Moscow, Russia
\end{abstract}

OPEN ACCESS

Edited by:

Pilar Marcos,

Universidad de Castilla La Mancha

Albacete, Spain

Reviewed by:

Paul M. Bingham,

Stony Brook University, United States

Giuseppe Caruso,

Associazione Oasi Maria SS. Onlus

(IRCCS), Italy

*Correspondence:

Yuri L. Dorokhov

dorokhov@genebee.msu.su

Specialty section:

This article was submitted to

Neuroenergetics, Nutrition and Brain

Health,

a section of the journal

Frontiers in Neuroscience

Received: 05 July 2017 Accepted: 09 November 2017 Published: 01 December 2017

Citation:

Shindyapina AV, Komarova TV

Sheshukova EV, Ershova NM, Tashlitsky VN, Kurkin AV, Yusupov IR, Mkrtchyan GV, Shagidulin MY and Dorokhov YL (2017) The Antioxidant

Cofactor Alpha-Lipoic Acid May Control Endogenous Formaldehyde Metabolism in Mammals.

Front. Neurosci. 11:651.

doi: 10.3389/fnins.2017.00651
The healthy human body contains small amounts of metabolic formaldehyde (FA) that mainly results from methanol oxidation by pectin methylesterase, which is active in a vegetable diet and in the gastrointestinal microbiome. With age, the ability to maintain a low level of FA decreases, which increases the risk of Alzheimer's disease and dementia. It has been shown that 1,2-dithiolane-3-pentanoic acid or alpha lipoic acid (ALA), a naturally occurring dithiol and antioxidant cofactor of mitochondrial $\alpha$-ketoacid dehydrogenases, increases glutathione (GSH) content and FA metabolism by mitochondrial aldehyde dehydrogenase $2(\mathrm{ALDH} 2)$ thus manifests a therapeutic potential beyond its antioxidant property. We suggested that ALA can contribute to a decrease in the FA content of mammals by acting on ALDH2 expression. To test this assumption, we administered ALA in mice in order to examine the effect on FA metabolism and collected blood samples for the measurement of FA. Our data revealed that ALA efficiently eliminated FA in mice. Without affecting the specific activity of FA-metabolizing enzymes ( $A D H 1, A L D H 2$, and ADH5), ALA increased the GSH content in the brain and up-regulated the expression of the FA-metabolizing $A L D H 2$ gene in the brain, particularly in the hippocampus, but did not impact its expression in the liver in vivo or in rat liver isolated from the rest of the body. After ALA administration in mice and in accordance with the increased content of brain ALDH2 mRNA, we detected increased ALDH2 activity in brain homogenates. We hypothesized that the beneficial effects of ALA on patients with Alzheimer's disease may be associated with accelerated ALDH2-mediated FA detoxification and clearance.

Keywords: endogenous methanol, formaldehyde, alpha-lipoic acid, glutathione, alcohol dehydrogenase, aldehyde dehydrogenase 2 , brain, hippocampus

\section{INTRODUCTION}

In mammals, the oxidation of metabolic short-chain alcohols, such as methanol $(\mathrm{MeOH})$ and ethanol (EtOH), occurs with the participation of enzymes from the class of alcohol dehydrogenase 1 (ADH1) (Cederbaum, 2012; Wang et al., 2012; Edenberg and Foroud, 2013; Dorokhov et al., 2015). $\mathrm{MeOH}$ produced by pectin methylesterases (PME) of the gastrointestinal microbiome or by plant 
PMEs consumed with vegetable food (Dorokhov et al., 2012, 2015; Komarova et al., 2014; Shindyapina et al., 2014) is invariably converted by the $\mathrm{ADH} 1$ enzyme to formaldehyde (FA) in mammalian organisms. $\mathrm{MeOH}$ is not the only source of metabolic FA; it may also be formed as a result of (a) semicarbazide-sensitive amine oxidase-mediated oxidative deamination of the methylamine derived from creatinine (Charlton and Mack, 1994; Lee et al., 2008) and (b) chromatin structure remodeling in the reaction of methyl groups removal from lysine residues in histones, which is catalyzed by lysinespecific demethylase 1 and $\mathrm{JmjC}$ domain-containing histone demethylases (Tsukada et al., 2006; Cloos et al., 2008; Hou and Yu, 2010; Walport et al., 2012; Liu et al., 2013).

FA appears to be the relevant agent in neurodegeneration (below); its oxidation to formic acid constitutes detoxification in this context. FA is converted to formic acid by the participation of enzymes mainly from the class of aldehyde dehydrogenase 2 (AlDH2) (Sládek, 2003; Sophos and Vasiliou, 2003). The oxidation of FA also occurs by the participation of ADH5 or the glutathione-dependent $\chi-\mathrm{ADH}$ FA dehydrogenase (FDH) enzyme (Tulpule et al., 2013). At the same time, it is known that catalase (CAT) (Cederbaum and Qureshi, 1982; Deng and Deitrich, 2008) and cytochrome P450 (CYP2E1) (Coon and Koop, 1987; Caro and Cederbaum, 2004; Wallage and Watterson, 2008) are included in the process of alcohol metabolism at high alcohol concentrations. It is important to note that in the tissues of the brain and liver, the regulation of the levels of $\mathrm{MeOH}$ occurs in different ways. The ADH1 enzyme oxidizes most of the $\mathrm{MeOH}$ in the human liver, while in brain cells, its activity is close to zero (Julià et al., 1987; Galter et al., 2003; Tulpule and Dringen, 2013). Apparently, the low activity of the ADH1 enzyme in human brain cells acts as a mechanism of protection against the harmful effects of FA on neurons (Tulpule and Dringen, 2013).

Chronic exposure to FA is known to cause acute health problems (Tang et al., 2009) related to amyloid aggregation (Chen et al., 2007), tau protein aggregation and hyperphosphorylation in vitro and in vivo (ENCODE Project Consortium et al., 2007; Liu et al., 2013; Su et al., 2016). It has been suggested that FA toxicity is related to the main hallmarks of age-related neuronal damage and Alzheimer's disease pathology (Tong et al., 2011, 2013a,b, 2017; Liu et al., 2013). The elevated levels of FA found in Alzheimer's disease (Tang et al., 2013a,b; Tong et al., 2013a, 2017) may play important roles in $\beta$-amyloid (A $\beta)$ aggregation and cerebral amyloid angiopathy (Li et al., 2016b).

An understanding of the mechanisms of FA metabolism and the ability to maintain a low level of its content in the human body open up the possibility of its control, reducing the risk of age-related neuronal damage and Alzheimer's disease pathology. In principle, there are two key strategies to balance the endogenous FA concentration: (i) inhibition of ADH1-mediated FA synthesis and (ii) stimulation of FA clearance through ALDH2 and ADH5 activation. The reality of the latter method was confirmed by the high detoxifying ability of $A L D H 2$ transgenic mice (Doser et al., 2009). Current knowledge of the factors that contribute to maintaining a low level of mammalian FA content is limited; however, one should take a closer look at the ways to alleviate the lives of patients suffering from Alzheimer's disease by potentially reducing the content of FA (Venigalla et al., 2016).
The list of nutraceuticals with antioxidant, neuroprotective, and cognition-enhancing properties contains alpha lipoic acid (ALA, 1,2-dithiolane-3-pentanoic acid) (Moura et al., 2015; Cronan, 2016), which has the potential for Alzheimer's disease prevention and treatment (Venigalla et al., 2016). There is evidence that ALA delays the aging process in the brain and improves brain function and memory. Studies on rat aging have suggested that ALA usage results in improved memory performance and delayed structural mitochondrial decay (Ames and Liu, 2004). Historically, the ability of ALA to ameliorate vitamin $\mathrm{C}$ and $\mathrm{E}$ deficiencies in laboratory guinea pigs and rats, respectively, first suggested that ALA functions as an antioxidant (Rosenberg and Culik, 1959). Oxidized and reduced (dihydrolipoic acid, DHLA) forms of ALA have been found to chelate heavy metals (Ou et al., 1995), scavenge various reactive oxygen species (ROS) (Packer et al., 1995), and affect antioxidant gene expression (Shay et al., 2009). Although only the R-ALA stereoisomer is found as a cofactor in ALA-containing enzymes, both enantiomers are effective scavengers of various ROS when they are administered exogenously (Bingham et al., 2014). DHLA can regenerate oxidized antioxidants, such as ascorbate (vitamin C), glutathione, coenzyme Q10, and vitamin E, thus reactivating them (Constantinescu et al., 1995). ALA also increases the levels of the most important water-soluble endogenous antioxidant, glutathione (GSH), in vivo and in vitro (Busse et al., 1992; Podda et al., 1994; Han et al., 1997; Sen et al., 1997). Glutathione reacts with FA, forming S-formylglutathione, which in turn is readily oxidized by ADH5. However, the possible participation of ALA in the metabolism of endogenous FA is not only based on its ability to increase GSH. Recent studies have shown that incubation with DHLA increases the activity of another FA-metabolizing enzyme-ALDH2 (He et al., 2012; Li et al., 2013; McCarty, 2013; Dudek et al., 2014) - by the reduction of disulphide bonds between the cysteines in the active site (Muñoz-Clares et al., 2017). A course of ALA injections resulted in elevated ALDH2 activity in human serum with coronary disease and in the gastric mucosa of rats treated with ethanol (Li et al., 2013, 2016a).

Thus, it can be assumed that ALA can perform the function of a regulator of ALDH2 activities in mammals and can thus control FA metabolism. To test this assumption, we investigated the effect of ALA on the metabolism of FA in mice. Our results showed that ALA is able to decrease exogenous and metabolic $\mathrm{MeOH}$ and FA levels in mice. The mechanism of FA elimination involves up-regulation of the genes responsible for its metabolism ( $A D H 1, A L D H 2, C A T, C Y P 2 E 1)$ in the hippocampus and spleen and elevated enzymatic activity of ALDH2 in mouse brain.

\section{MATERIALS AND METHODS}

\section{Materials}

$\beta$-nicotinamide adenine dinucleotide, acetonitrile (HPLC grade) and Triton X-100 were purchased from PanReac AppliChem, Halt Protease Inhibitor Cocktail (100X) and 16\% methanol-free formaldehyde from Thermo Fisher Scientific, TriReagent from MRC. Alda-1 was synthesized by Dr. A.V. Kurkin (Moscow State University, Russia). All other chemicals were from Sigma Aldrich (Vienna, Austria) if not specified otherwise. 


\section{Animals and in Vivo Treatment}

Animal procedures were in accordance with Guide for the Care and Use of Laboratory Animals as adopted and promulgated by the U.S. National Institutes of Health and permission was granted by the ethical committee of the A. N. Belozersky Institute of Physico-Chemical Biology at Lomonosov Moscow State University, Moscow, Russia (protocol number 4 from May 12, 2016). All mice used in the study were female nonpregnant Balb/c mice with weights of $28-34 \mathrm{~g}$. Liver perfusion was performed on Wistar male rats. The animals were fed a cereal-based diet consisting of $12.7 \%$ protein, $5.6 \%$ fat, and $54.1 \%$ carbohydrate with a total fiber content of $3.7 \%$. The diet was supplemented with a vitamin-mineral premix according to the recommendation of the American Institute of Nutrition (AIN93M diet). Mice were randomly assigned to 3 groups of five and were injected i.p. with $300 \mu \mathrm{l}$ of normal saline or 4-MP (10 $\mathrm{mg} / \mathrm{kg}$ ) with corresponding volume of ALA vehicle in normal saline or a mix of ALA $(20 \mathrm{mg} / \mathrm{kg})$ and $4-\mathrm{MP}(10 \mathrm{mg} / \mathrm{kg})$ in normal saline. The same protocol was used for Alda-1 (8.5 $\mathrm{mg} / \mathrm{kg}$ ) treatment. For the treatment with ascorbic acid, mice were assigned to two groups of three and were injected i.p. with $300 \mu \mathrm{l}$ of $4-\mathrm{MP}(10 \mathrm{mg} / \mathrm{kg})$ or the same volume of a mix of ascorbic acid $(200 \mathrm{mg} / \mathrm{kg})$ and $4-\mathrm{MP}(10 \mathrm{mg} / \mathrm{kg})$ in normal saline. Approximately $100 \mu \mathrm{l}$ of $4-\mathrm{MP}(10 \mathrm{mg} / \mathrm{kg})$ in olive oil or a mix of $4-\mathrm{MP}(10 \mathrm{mg} / \mathrm{kg})$ and tocopherol $(100 \mathrm{mg} / \mathrm{kg})$ in olive oil were orally administered. Blood samples (50-100 $\mu \mathrm{l})$, whole brain and liver were collected $90 \mathrm{~min}$ later. Liver and brain tissues were immediately flash-frozen in liquid nitrogen and homogenized, and 50-100 mg was transferred to $1-1.5 \mathrm{ml}$ of TriReagent. Total RNA was extracted by TriReagent according to the manufacturer's protocol. Blood samples were incubated at $25^{\circ} \mathrm{C}$ for clot formation. Plasma was separated by centrifugation at $700 \mathrm{~g}$ for $20 \mathrm{~min}\left(4^{\circ} \mathrm{C}\right)$, transferred to sterile tubes and mixed with an equal volume of $10 \%$ trichloroacetic acid (TCA) for FA measurement or with an equal volume of acetonitrile supplemented with $1 \%$ Triton X-100 for $\mathrm{MeOH}$ measurement. The mixtures were incubated for 20 min on ice and were then centrifuged for $10 \mathrm{~min}$ at $16,000 \mathrm{~g}$. Finally, the supernatant was transferred to sterile tubes and analyzed for $\mathrm{MeOH}$ and FA content by HPLC and gas chromatography (GC), respectively. Expression analysis was blinded for chemical injection and RNA extraction.

\section{Rat Liver Perfusion Technique}

All manipulations were carried out under sterile conditions, taking into account the aseptic and antiseptic requirements. Anaesthesia of experimental animals was carried out by injecting the solution Zoletil 50 (Virbac Sante Animale, France) into the abdominal cavity at a dosage of $7.5 \mathrm{mg} / \mathrm{kg}$ body weight. For the purpose of systemic heparinization, heparin was administered to the penile vein at a dose of 200 units. Then, median laparotomy was performed. Using a special cannula (Venflon $1.3 \times 45 \mathrm{~mm}$ ), the portal vein (Vena portae) was cannulated and an additional 150 units of heparin was added to the portal vein. Immediately after this, the subhepatic branch of the portal vein was ligated. Liver washing from the blood elements was performed with oxygenated $\left(95 \% \quad \mathrm{O}_{2}\right.$ and $\left.5 \% \mathrm{CO}_{2}\right)$ Krebs-Henseleit buffer
(118 mM NaCl, $4.5 \mathrm{mM} \mathrm{KCl,} 2.75 \mathrm{mM} \mathrm{CaCl}_{2}, 1.19 \mathrm{mM} \mathrm{KH}_{2} \mathrm{PO}_{4}$, $1.18 \mathrm{mM} \mathrm{MgSO}_{4}$ and $25 \mathrm{mM} \mathrm{NaHCO}_{3}, \mathrm{pH} 7.4$ at $t=37.8^{\circ} \mathrm{C}$ ) in a volume of $500 \mathrm{ml}$ with a peristaltic pump, creating a flow rate of $2.5-4.0 \mathrm{ml} / \mathrm{min} / \mathrm{g}$ and a physiological pressure of $\sim 12-15 \mathrm{~mm}$ $\mathrm{Hg}$ in the portal vein. A recirculating perfusion system was used. In the pleural part, the suprahepatic branch of the vena cava was dissected and the perfusate was removed. The quality of liver perfusion was evaluated based on the organ integrity, uniformity of pale color, and consistency (degree of oedema). After washing blood elements from the liver, liver explantation was performed and isolated perfusion was carried out. $\mathrm{MeOH}(120 \mathrm{mg} / \mathrm{kg})$ and ALA (20 mg/kg) were sequentially added to the upper perfusate reservoir. Samples were taken every $15 \mathrm{~min}$ for an hour with $2 \mathrm{ml}$ perfusate.

\section{Liver Enzyme Analysis}

Measurements of AST, ALT, and ALP were carried out on an Analyser A25 (Biosystems, Spain) with commercial kits produced by Hospitex Diagnostics (Italy) according to the manufacturer's instructions. The spectrophotometer was calibrated before each enzyme measurement.

\section{FA Measurement by HPLC}

All analytical studies were performed on a Dionex Ultimate 3000 (Thermo Fisher, USA), including a quaternary gradient pump, mobile phase degasser, automatic injector and spectrophotometric detector affording continuously variable wavelengths. A reversed phase analytical column, Synergi Hydro$\mathrm{RP}, 250 \times 4.6 \mathrm{~mm}, 4 \mu \mathrm{m}$ sorbent (Phenomenex, USA) was used for the analysis. The mobile phase was water-acetonitrile (50:50, v/v). The detection wavelength was set at $360 \mathrm{~nm}$. The injection volume was $20 \mu \mathrm{l}$ with a flow rate of $1.0 \mathrm{ml} / \mathrm{min}$. The $0.1 \%$ reagent solution was prepared by adding $20 \mathrm{mg}$ of 2,4-dinitrophenylhydrazine hydrochloride (DPH) reagent (TCI, Japan) to $20 \mathrm{ml}$ of acetonitrile and $100 \mu \mathrm{l}$ of $85 \%$ phosphoric acid. To a $20-\mathrm{ml}$ scintillation vial, $50 \mu \mathrm{L}$ of the cleared sample, $450 \mu \mathrm{L}$ of deionized water, $2.5 \mu \mathrm{l}$ of phosphoric acid (85\%), and $0.5 \mathrm{ml}$ of the $0.1 \% \mathrm{DPH}$ reagent were added. Blank samples were prepared by mixing $0.5 \mathrm{ml}$ of the $0.1 \% \mathrm{DPH}$ reagent with $0.5 \mathrm{ml}$ of deionized water. Formaldehyde was quantitatively converted to the Schiff base in $20 \mathrm{~min}$ at $22-24^{\circ} \mathrm{C}$. The resultant solution was analyzed by HPLC. Concentrations were quantified according to the equation $\mathrm{C}(\mathrm{mg} / \mathrm{L})=($ Sx-Sblank $) / 14.36^{*} 20$, where 14.36 is the calibration coefficient and 20 is the dilution factor. Measurements of FA were blinded for the HPLC operator.

\section{MeOH Measurements by GC}

$\mathrm{MeOH}$ content was analyzed on chromatograph Kristall 5000 (Chromatek, Russia) in the following conditions: column SolGel Wax $30^{*} 0.25^{*} 0.25$, and the flame ionization detector (FID), temperature and injector temperature were set to $220^{\circ} \mathrm{C}$. The oven temperature was held for $1 \mathrm{~min}$ at $50^{\circ} \mathrm{C}$, followed by an increase at $20^{\circ} \mathrm{C} / \mathrm{min}$ to $100^{\circ} \mathrm{C}$ (hold for $1 \mathrm{~min}$ ) and ending at $200^{\circ} \mathrm{C}$ after an increase at a rate of $20^{\circ} \mathrm{C} / \mathrm{min}$. Nitrogen, hydrogen and air flows were 30,40 , and $400 \mathrm{ml} / \mathrm{min}$, respectively. The injection volume of samples was $1 \mu \mathrm{l}$. 


\section{qRT-PCR}

RNA concentrations were determined using a Nanodrop ND1000 spectrophotometer (Isogen Life Sciences). All RNA samples had a 260/280 absorbance ratio between 1.9 and 2.1.

cDNA was obtained by annealing $2 \mu \mathrm{g}$ of denatured total RNA with $0.1 \mu \mathrm{g}$ of random hexamers and $0.1 \mu \mathrm{g}$ of Oligo-dT. The mixture was then incubated with 200 units of Superscript II reverse transcriptase (Invitrogen, USA) for $50 \mathrm{~min}$ at $43^{\circ} \mathrm{C}$. The qRT-PCR was performed using the iCycler iQ real-time PCR detection system (Bio-Rad, Hercules, CA, USA). For the detection of target genes, the Eva Green master mix (Syntol, Russia) was used according to the manufacturer's instructions. The thermal profile for EVA Green qRT-PCR included an initial heat-denaturing step at $95^{\circ} \mathrm{C}$ for $3 \mathrm{~min}$ and 45 cycles at $95^{\circ} \mathrm{C}$ for $15 \mathrm{~s}$ and an annealing step for $30 \mathrm{~s}$ and $72^{\circ} \mathrm{C}$ for $30 \mathrm{~s}$ coupled with fluorescence measurements. Following amplification, the melting curves of the PCR products were monitored from 55 to $95^{\circ} \mathrm{C}$ to determine the specificity of amplification. Each sample was run in triplicate, and a non-template control was added to each run. Target gene mRNA levels were calculated according to the equation proposed by Pfaffl (2001): $\mathrm{E}_{\text {target }}^{\Delta \mathrm{CPtarget} \text { (sample-reference) }}$. PCR efficiency (E) was calculated according to the equation $\mathrm{E}=10^{(-1 / \text { slope })}$ based on the standard curves. Target gene mRNA levels were corrected using the corresponding reference genes. Expression analysis was blinded for the qRT-PCR operator. The oligonucleotides used for qRT-PCR are listed in Table S1.

\section{Measurement of ALDH2 Enzymatic Activity in Mouse Brain}

The mice were administered ALA ( $20 \mathrm{mg} / \mathrm{kg})$ concomitantly with 4-MP $(10 \mathrm{mg} / \mathrm{kg})$, and $90 \mathrm{~min}$ later, the brain total fractions of the mitochondrial and cytoplasmic proteins were separated as described previously (Bunik et al., 2008). The ALDH2 assay was carried out in $200 \mu \mathrm{l}$ containing $50 \mathrm{mM}$ sodium pyrophosphate buffer $\mathrm{pH} 8.1,0.1 \mathrm{mM} \mathrm{NAD}^{+}, 50 \mathrm{mM}$ FA and $20 \mu \mathrm{l}$ of the brain mitochondrial fraction. ALDH2 and the background reactions (without FA) were recorded in parallel for $20 \mathrm{~min}$ at $340 \mathrm{~nm}$ in the black plates $\left(25^{\circ} \mathrm{C}\right)$. The activities of ALDH2 were normalized for the total protein content (mg) measured by a Pierce BCA Protein Assay kit according to the manufacturer's protocol.

\section{GSH Measurement in Mouse Brain}

GSH was measured using 5,5'-dithio-bis(2-nitrobenzoic acid) (DTNB). Cytoplasmic cell fractions $(80 \mu \mathrm{l})$ were mixed with $30 \mu \mathrm{l} 10 \mathrm{mM}$ DTNB and $0.2 \mathrm{M} \mathrm{Na}_{2} \mathrm{HPO}_{4}$ to a final volume of $300 \mu \mathrm{l}$ and $15 \mathrm{~min}$ later absorbance was recorded at $412 \mathrm{~nm}$. The concentrations of GSH were normalized for the total protein content (mg) measured by a Pierce BCA Protein Assay kit according to the manufacturer's protocol.

\section{Synthesis of Microarrays}

B3 microarray synthesizer (CustomArray, USA) was used for 40 nucleotides-long oligonucleotide probe synthesis on CustomArray ECD $4 \mathrm{X} 2 \mathrm{~K} / 12 \mathrm{~K}$ slides. Synthesis was performed according to the manufacturer's recommendations. Two replicates of total 6,020 unique oligonucleotide probes specific to 2,091 mice gene transcripts were placed on each chip. Chip design was performed using Layout Designer software (CustomArray, USA). For the custom microchip, we used original oligonucleotide probe sequences of the Illumina HT 12 v4 platform.

\section{Library Preparation and Hybridization}

Complete Whole Transcriptome Amplification WTA2 Kit (Sigma) was used for reverse transcription and library amplification. Manufacturer's protocol was modified by adding to amplification reaction dNTP mix containing biotinylated dUTP, resulting to final proportion dTTP/biotin-dUTP as $5 / 1$. Microarray hybridization was performed according to
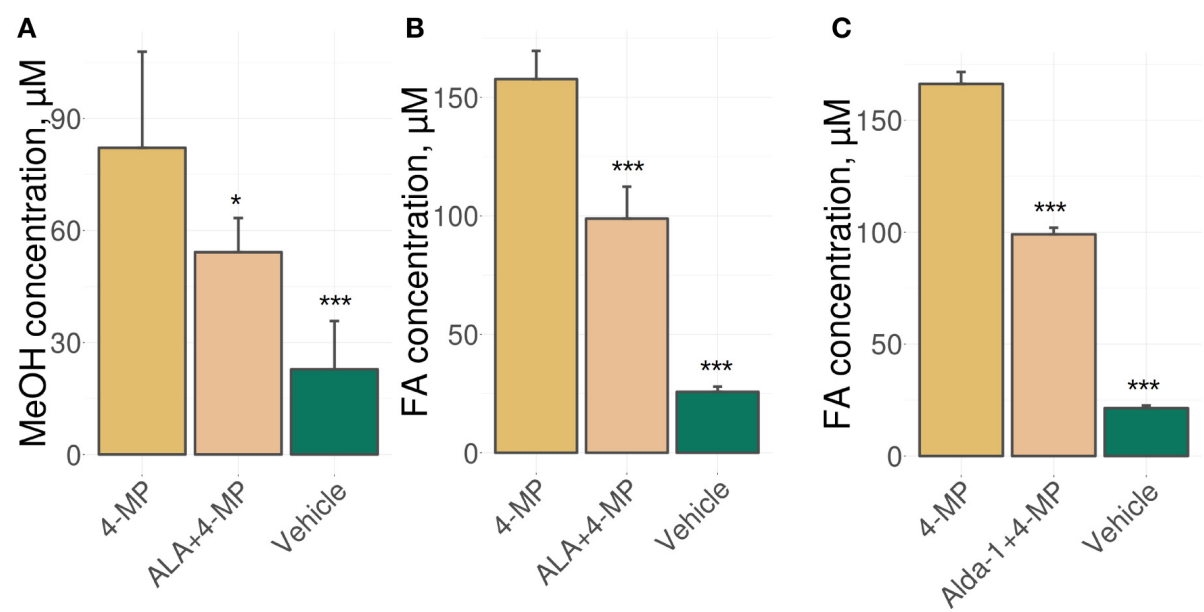

FIGURE 1 | ALA intake decreases the MeOH and FA content in mouse blood. (A-C) The mice were administered ALA (20 mg/kg) (A,B) or Alda-1 (8.5 mg/kg) (C) concomitantly with 4-MP (10 mg/kg), and 90 min later, the MeOH (A) and FA (B,C) content of the blood was analyzed by GC and HPLC analyses, respectively. The mice were randomly divided into groups of five and received mixture of ALA or Alda-1 and 4-MP in normal saline or only normal saline solution in the control group. The data represent five independent experiments, and standard error bars are indicated. $P$-values (Mann-Whitney $U$-test) are designated by: ${ }^{\star \star \star} P<0.001 ;{ }^{\star} P<0.05$. 
the CustomArray ElectraSense ${ }^{\mathrm{TM}}$ Hybridization and Detection protocol. Hybridization mix contained $2.5 \mu \mathrm{g}$ of labeleled DNA library, 6X SSPE, 0.05\% Tween-20, 20 mM EDTA, 5x Denhardt solution, $100 \mathrm{ng} / \mu \mathrm{l}$ sonicated calf thymus gDNA, 0.05\% SDS. Hybridization mix was incubated with chip overnight at $50^{\circ} \mathrm{C}$. Hybridization efficiency was detected electrochemically using CustomArray ElectraSense ${ }^{\mathrm{TM}}$ Detection Kit and ElectraSense $\mathrm{T}^{\mathrm{TM}}$ $4 \mathrm{X} 2 \mathrm{~K} / 12 \mathrm{~K}$ Reader.

\section{Statistical Analysis}

$P$-values were calculated using the Mann-Whitney test or paired Student's $t$-test by R (R: The R Project for Statistical Computing). The boxes of the boxplots represent the median with $25 \%$ and $75 \%$ percentiles, the bottom whisker is the minimal value, the top whisker is the maximal value, and the outliers are plotted as spots. The barplot heights are the means with standard deviation error bars. Statistical analyses were programmed in R using the Rstudio soft.

\section{RESULTS}

\section{ALA Influence on the $\mathrm{MeOH}$ and FA Content in Mice Blood}

We used an experimental approach in which mice were administered ALA concomitantly with 4-MP and showed that the administration of ALA (20 mg/kg) and 4-MP (10 mg/kg) led to statistically significant reductions of $\mathrm{MeOH}$ (Figure 1A) and FA (Figure 1B) content in the blood. The administration of Alda1, an activator of ALDH2 (Chen et al., 2008; Perez-Miller et al., 2010), also lowered FA in mouse blood (Figure 1C). The results raise questions on the mechanism of ALA action on $\mathrm{MeOH}$ and FA metabolism. Because ALA is a multifunctional natural agent with antioxidative properties (Fujita et al., 2008; Kamarudin et al., 2014; Shi et al., 2016), we tested ascorbic acid and tocopherol, known natural antioxidants (Halliwell, 2006), for their ability to influence $\mathrm{MeOH}$ and FA metabolism in mice. Surprisingly, there was no difference in the serum levels of $\mathrm{MeOH}$ and FA between the mice treated with ascorbic acid $(200 \mathrm{mg} / \mathrm{kg})$ or tocopherol $(100 \mathrm{mg} / \mathrm{kg}$ ) and the control groups (Figure S1).

Thus, we concluded that the ability of ALA to exert a diminishing effect on the metabolic content of $\mathrm{MeOH}$ and FA does not appear to be directly related to its antioxidant properties.

\section{Investigation of the ALA Effect on Hepatic Detoxification Function in a Perfused Rat Liver Model}

The liver is the main site for the synthesis of ALA (Mayr et al., 2014; Cronan, 2016) as well as $\mathrm{MeOH}$ metabolism, and it could be assumed that the liver is the organ of

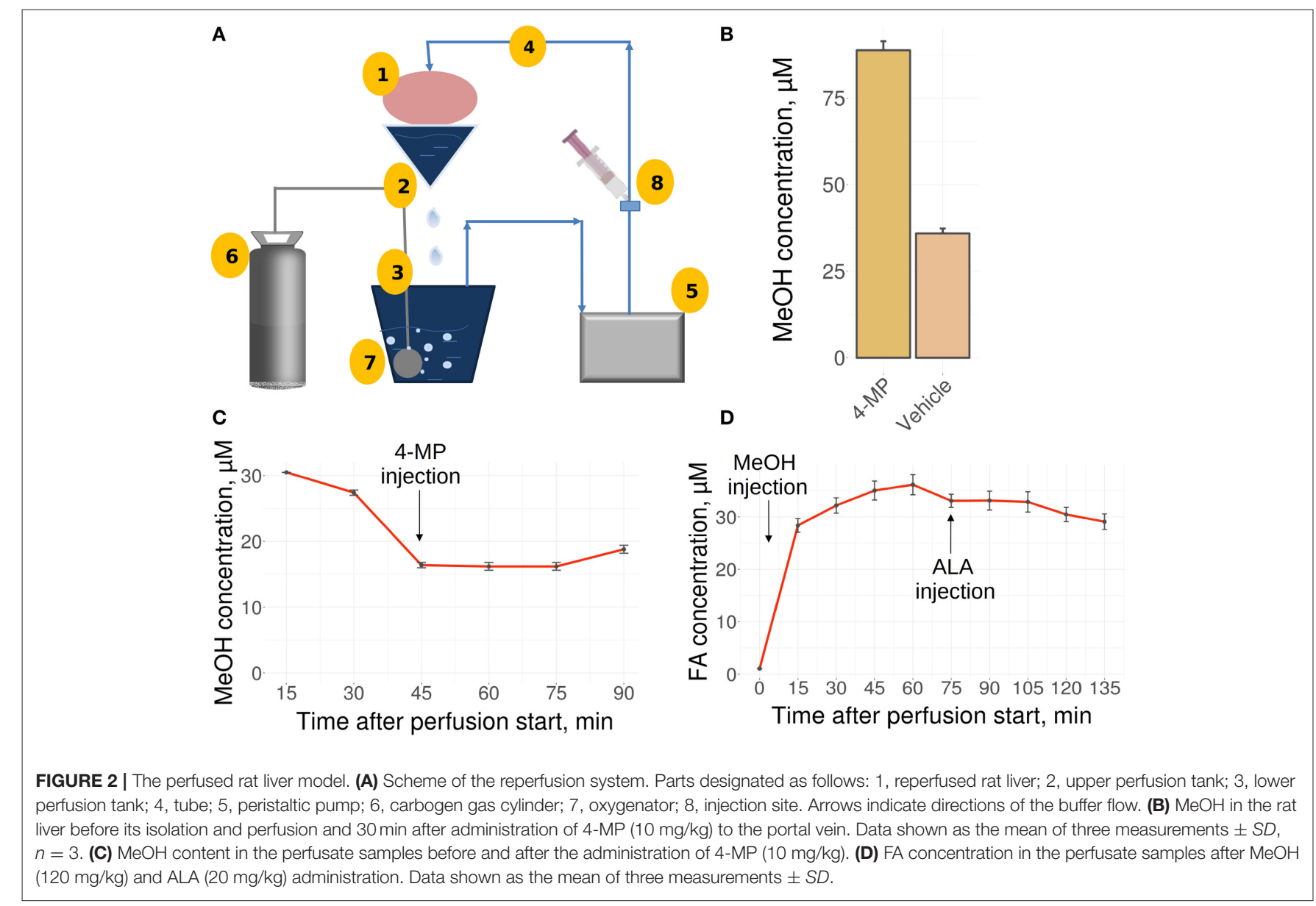


$\mathrm{MeOH}$ generation and FA content control in mammals. To confirm these assumptions, we used a perfused rat liver model (Figure 2A) that preserved the biosynthetic activity of hepatic cells both immediately after organ isolation (Table S2) and during subsequent manipulations (Table S3). When the liver was still connected to the gastrointestinal tract, the introduction of 4MP into the portal vein led to the accumulation of $\mathrm{MeOH}$ in its tissues (Figure 2B). However, the isolated liver, which had ceased all connections with the rest of the body, lost its ability to respond to both 4-MP (Figure 2C) and ALA (Figure 2D).

We concluded that the isolated rat liver failed to generate $\mathrm{MeOH}$ and is not sensitive to exogenous ALA.

\section{ALA Influence on mRNA Accumulation in Mouse Organs}

To understand which organs react to ALA intake, we analyzed the mRNA content for FA-metabolizing genes. Relative levels of mRNA were quantified by qRT-PCR in mouse brain (whole brain, hippocampus, cortex, cerebellum, and the rest of brain), kidney, spleen, heart, and liver samples. For the analysis, we selected genes that encode key $\mathrm{MeOH}$-metabolizing enzymes (ADH1, ALDH2, CAT, CYP2E1, and ADH5) and NRF2, which is encoded by the NFE2L2 gene and is a well-known sensor of oxidative stress (Prasad, 2016). Our analysis showed that
ALA intake does not change the mRNA content of the studied genes in the liver (Figure 3E) or the kidney (Figure 3I). The heart responded to ALA with a rise in the content of only CYP2E1 mRNA (Figure 3D). The spleen (Figure 3C) reacted to ALA by increasing the content of ADH1, CYP2E1, and $A D H 5$ mRNAs. The brain as a whole demonstrated the ability to accumulate the mRNA of genes responsible for FA detoxification (Figure 3A). Apparently, the hippocampus (Figure 3B) is responsible for the responsiveness of the brain to ALA the rest parts of the brain did not reflect any changes (Figures 3F-H).

We concluded that the brain, along with the spleen, are sensitive to the action of ALA and are involved in maintaining a low level of FA in mammals.

\section{ALA Increases GSH Synthesis and Accelerates FA Metabolism by Activation of the Brain ALDH2 Enzyme}

Biologically, ALA ameliorates oxidative stress in the mammalian brain, and this mechanism includes increasing the total GSH level (Panigrahi et al., 1996; Suh et al., 2004). Figure 4A, in accordance with our expectations, shows that ALA stimulated GSH accumulation in mouse brain. By stimulating accumulation

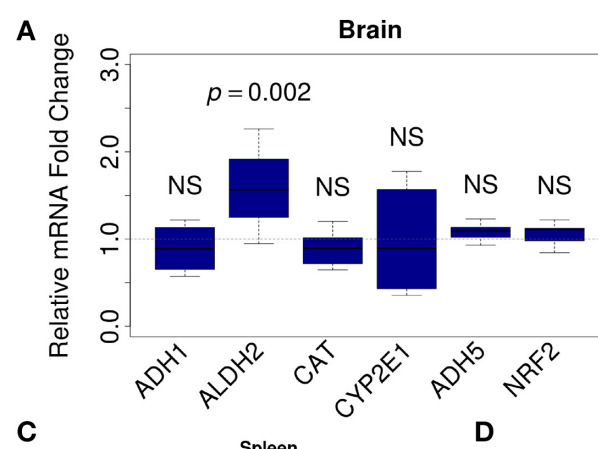

B
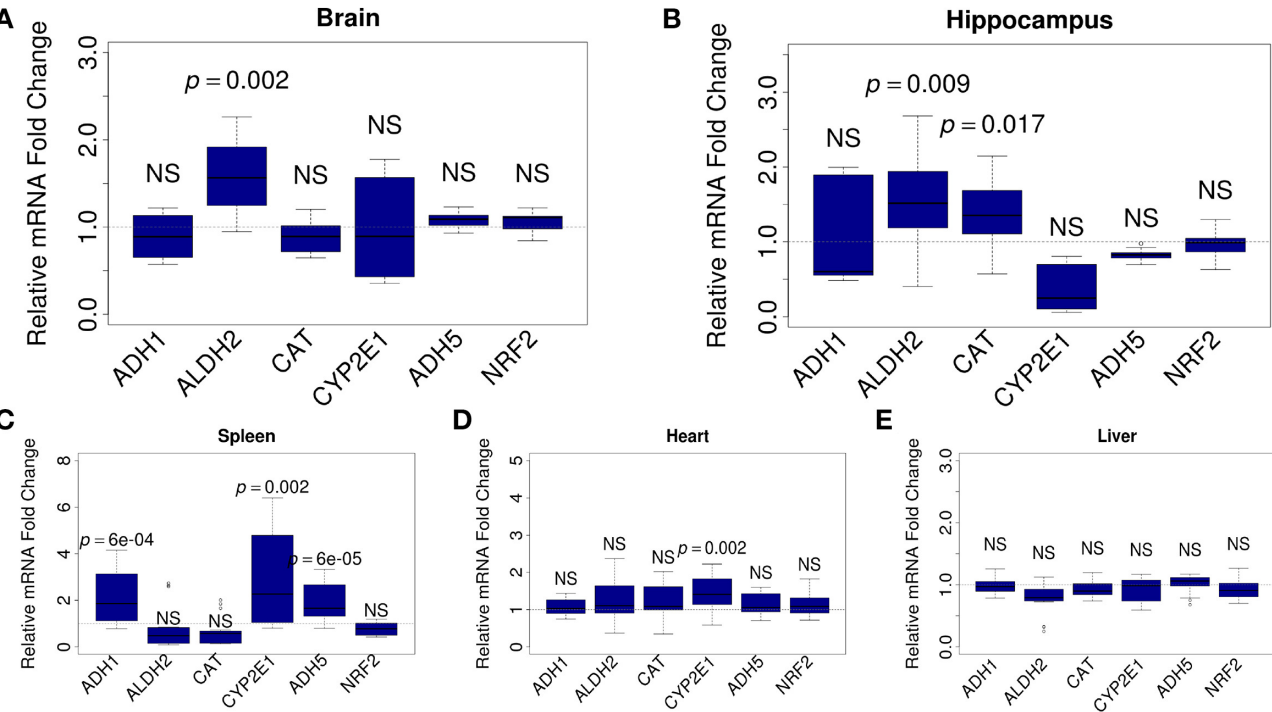

D Heart

E
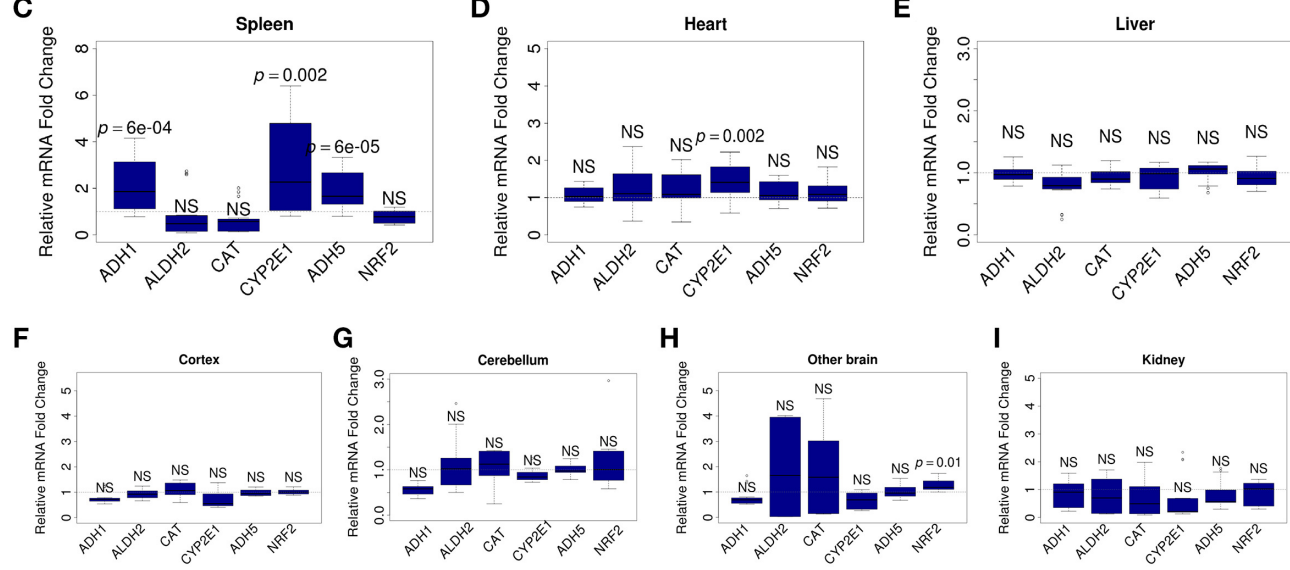

FIGURE 3 | ALA promotes the accumulation of FA-metabolizing gene mRNAs in mouse organs. The mice were administered ALA (20 mg/kg) concomitantly with 4-MP (10 mg/kg) or 4-MP only, and 90 min later, the mRNA content in the whole brain $(n=22)(\mathbf{A})$ and brain hippocampus $(n=12)(\mathbf{B})$, spleen $(n=12) \mathbf{( C )}$, heart $(n=$ 12) (D), and liver $(n=22)(\mathbf{E})$, cortex $(n=12)(\mathbf{F})$, cerebellum $(n=12)(\mathbf{G})$, other brain $(n=12)(\mathbf{H})$, and kidney $(n=12)(\mathbf{I})$ was quantified by qRT-PCR. The relative quantities of mRNA after ALA+4-MP intake were normalized to the mRNA levels after 4-MP injection. The data represent two independent experiments. $P$-values (Mann-Whitney U-test) vs. 4-MP group are shown; NS- not significant. 
of the mRNA of detoxifying genes, ALA should also increase the enzymatic activity of their products. To test this assumption, we investigated the enzymatic activity of ALDH2 in the brain extracts of mice after ALA intake. Figure 4B shows the elevated activity of ALDH2 FA-metabolizing enzymes in mouse brains. To exclude the effect of ALA on the specific activity of enzymes, we tested isolated enzymes in vitro using various substrates. Figure $\mathbf{S 2}$ shows that neither a racemic mixture of ALA or individual isomers (R- and S-ALA) notably affect the activity of ALDH2, ADH5 and ADH1 in liver and brain homogenates in vitro.

We concluded that ALA increases the detoxification activity of ALDH2 in the mouse brain without affecting its specific activity.

\section{DISCUSSION}

ALA is widely used as antioxidant in clinical practice (Venigalla et al., 2016) and as a biologically active additive (Ziegler et al., 1995, 1999; Shay et al., 2009).

For the first time, we demonstrated that ALA is able to reduce the level of endogenous FA in mice. Since ALA reduces the content of both FA and $\mathrm{MeOH}$ in the blood of mice (Figure 1), we concluded that ALA activated the FA and $\mathrm{MeOH}$ oxidation system rather than alternative mechanisms of FA clearance. Expression analysis of the FA-metabolizing gene cluster revealed that ALA intake increased the accumulation of mRNA from FA-metabolizing genes in mouse brains in general,

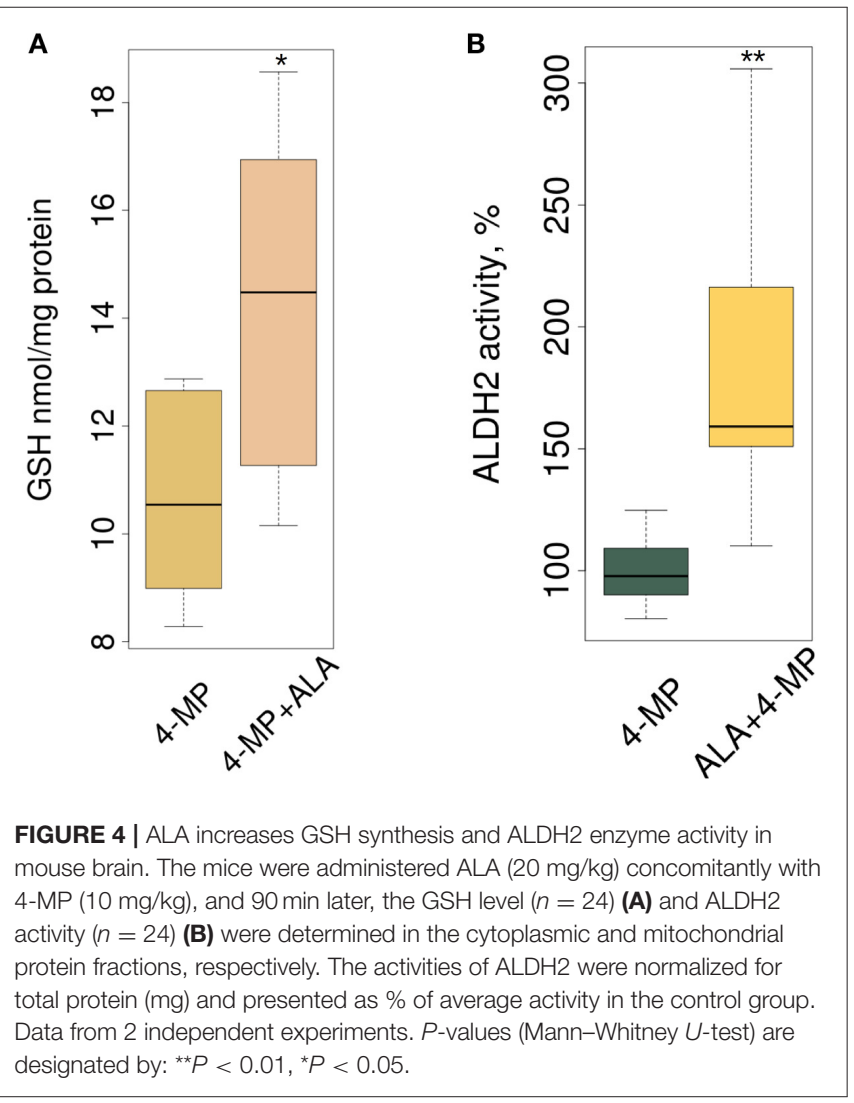

particularly in the mouse hippocampus $(A L D H 2, C A T)$ and spleen (ADH1, CYP2E1, ADH5) (Figure 3). It has been suggested that ALA predominantly ameliorates oxidative stress in the mammalian brain through NRF2 activation (Macias-Barragan et al., 2017). However, our qRT-PCR (Figure 3) and microarray data (Table S4) of mouse brains did not reveal any changes in NFE2L2 mRNA levels and signaling pathway, indicating that the observed ALA effects on gene expression are mediated by another signaling pathway. On the other hand, our enrichment analysis of differentially expressed genes in the mouse brain in response to ALA and 4-MP vs. 4-MP suggested the potential involvement of the mTOR/S6K1 (Figure S3) and AKT/PI3K (Figure S4) pathways. This possibility is supported by previous reports of effects of ALA on mammalian cells mediated by both of these pathways (Lv et al., 2014; Ma et al., 2016; Dong et al., 2017).

Intriguingly, there was no ALA effect in mouse liver or in a rat liver isolated from the rest of the body (Figure 2). It can be assumed that although the liver is the main organ of ALA synthesis (Hiltunen et al., 2010), ALA targets are located somewhere outside of the liver. Our results showed that the brain is the main organ of ALA effects, and this result is consistent with known data that indicate the ability of ALA to alleviate oxidative stress and affect gene expression in the brain. The mechanism of ALA activation of the $A L D H 2$ gene in brain cells is unknown.

Although natural antioxidants, namely, vitamins $\mathrm{C}$ and $\mathrm{E}$, did not change blood FA (Figure S1), the possibility that the antioxidant properties of ALA are also involved in the activation of the ALDH2 gene in brain cells cannot be excluded. Particular molecules can exhibit cell type-specific antioxidant activities, and their activities can differ depending on the study model that is chosen (Caruso et al., 2017).

It can be assumed that ALA directly or indirectly affects elements of the transcriptional promoter sensitive to acetaldehyde (Ishikawa et al., 2007; Kimura et al., 2009). Our analysis of the ALDH2 promoter $(-2,000 \ldots-1$ relative to the transcription start site) by UniPROBE (Hume et al., 2015) found 78 distinct transcription factors that bind it in vitro. Two of them, SMAD3 and EGR1, are up-regulated in our array data (Table S4), and thus they could be responsible for ALDH2 regulation by ALA.

In the current work, the involvement of ALA in maintaining a low level of FA in mice explains the results of published studies, revealing a relationship between the elevated level of endogenous FA and neurodegeneration in humans (Tang et al., 2013a,b; Tong et al., 2013a, 2017). Our knowledge of the roles of ALA in health and disease permits the customization of existing and future therapeutic and prophylactic modalities.

\section{AUTHOR CONTRIBUTIONS}

YD, AS, and TK conceptualized the topic and designed the experiments. AS and ES performed most of the experiments. NE, VT, AK, GM, IY, and MS conducted some experiments. YD, AS, and TK evaluated the data and drafted the skeleton of 
manuscript. YD, AS, TK revised and finalized the manuscript. All the authors read and approved the manuscript.

\section{ACKNOWLEDGMENTS}

The work of AS, ES, TK, and YD concerning RT-PCR analysis of animal samples was performed at N.I. Vavilov Institute of General Genetics of RAS and funded by the Russian Science Foundation (project No. 16-14-00002). The work of AS in the part of studying the methanol and formaldehyde metabolism was performed at N.I. Vavilov Institute of General Genetics of RAS and funded by the Russian Foundation of Basic Research (project No. 16-34-00379). The funding institution had no role in study design, data collection and analysis, decision to publish, or preparation of the manuscript.

\section{SUPPLEMENTARY MATERIAL}

The Supplementary Material for this article can be found online at: https://www.frontiersin.org/articles/10.3389/fnins. 2017.00651/full\#supplementary-material

Figure S1 | Ascorbic acid and tocopherol do not influence FA level in the mice serum. The mice were administered ascorbate $(200 \mathrm{mg} / \mathrm{kg}, n=3)$ or tocopherol (100 mg/kg, $n=3$ ) concomitantly with 4-MP (10 mg/kg), and 60 min later FA content of the blood was analyzed by HPLC analyses. The mice were randomly divided into groups of three. Data presented as boxplots, where every dot designate one biological replica. NSS, not stastically significant (Student's $t$-test).

Figure S2 | ALA failed to alter ALDH2, ADH5 and ADH1 activities in vitro. ALDH2 activity was measured in presence of ALA in the mitochondrial protein fraction of liver samples with acetaldehyde (AA) (A) or FA (B) as substrates. ADH activity was measured in presence of ALA in the cytoplasmic protein fraction of liver or brain

\section{REFERENCES}

Ames, B. N., and Liu, J. (2004). Delaying the mitochondrial decay of aging with acetylcarnitine. Ann. N. Y. Acad. Sci. 1033, 108-116. doi: 10.1196/annals. 1320.010

Bingham, P. M., Stuart, S. D., and Zachar, Z. (2014). Lipoic acid and lipoic acid analogs in cancer metabolism and chemotherapy. Expert Rev. Clin. Pharmacol. 7, 837-846. doi: 10.1586/17512433.2014.966816

Bunik, V., Kaehne, T., Degtyarev, D., Shcherbakova, T., and Reiser, G. (2008). Novel isoenzyme of 2-oxoglutarate dehydrogenase is identified in brain, but not in heart. FEBS J. 275, 4990-5006. doi: 10.1111/j.1742-4658.2008.06632.x

Busse, E., Zimmer, G., Schopohl, B., and Kornhuber, B. (1992). Influence of alpha-lipoic acid on intracellular glutathione in vitro and in vivo. Arzneimittelforschung 42, 829-831.

Caro, A. A., and Cederbaum, A. I. (2004). Oxidative stress, toxicology, and pharmacology of CYP2E1. Annu. Rev. Pharmacol. Toxicol. 44, 27-42. doi: 10.1146/annurev.pharmtox.44.101802.121704

Caruso, G., Fresta, C. G., Martinez-Becerra, F., Antonio, L., Johnson, R. T., de Campos, R. P. S., et al. (2017). Carnosine modulates nitric oxide in stimulated murine RAW 264.7 macrophages. Mol. Cell. Biochem. 431, 197-210. doi: 10.1007/s11010-017-2991-3

Cederbaum, A. I. (2012). Alcohol metabolism. Clin. Liver Dis. 16, 667-685. doi: 10.1016/j.cld.2012.08.002

Cederbaum, A. I., and Qureshi, A. (1982). Role of catalase and hydroxyl radicals in the oxidation of methanol by rat liver microsomes. Biochem. Pharmacol. 31, 329-335. doi: 10.1016/0006-2952(82)90179-4

Charlton, C. G., and Mack, J. (1994). Substantia nigra degeneration and tyrosine hydroxylase depletion caused by excess S-adenosylmethionine in the rat brain. Support for an excess methylation hypothesis samples with $\mathrm{EtOH}(\mathbf{C , D})$ or $\mathrm{MeOH}(\mathbf{E}, \mathbf{F})$ as substrates. ADH5 activity was measured in the presence of ALA in the cytoplasmic protein fraction of liver samples with FA and glutathione (GSH) as substrates (G). Standard error bars represent the means of triplicate measurements. Asterisks designate data from 2 independent experiments. Activity of the enzymes was calculated as $\Delta \mathrm{A} / \mathrm{min}$ and was presented as \% of average activity in the vehicle group.

Figure S3 | ALA affects expression of the genes involved in the mTOR signaling pathway. Scheme was colored according to enrichment analysis by DAVID (https://david.ncifcrf.gov/) of the differentially expressed genes in the mice brain treated with ALA and 4-MP vs. 4-MP control. Red color designate the up-regulated genes, blue color-down-regulated. Scheme and coloring were conducted by KEGG Mapper tools (http://www.genome.jp/kegg/tool/ map_pathway2.html).

Figure S4 | ALA affects expression of the genes involved in the AKT/PI3K signaling pathway. Scheme was colored according to enrichment analysis by DAVID (https://david.ncifcrf.gov/) of the differentially expressed genes in the mice brain treated with ALA and 4-MP vs. 4-MP control. Red color designate the up-regulated genes, blue color-down-regulated. Scheme and coloring were conducted by KEGG Mapper tools (http://www.genome.jp/kegg/tool/ map_pathway2.html).

\section{Table S1 | Oligonucleotides used for qPCR.}

Table S2 | Level of ALP, ALT, and AST in the reperfused fluid from the intact isolated rat liver 15 and 30 min after isolation. Data presented as the means $\pm S D$ of duplicate measurements. ALP, alkaline phosphatase; ALT, alanine aminotransferase; AST, aspartate aminotransferase; ND, not detected.

Table S3 | Level of ALP, ALT, and AST in the reperfused fluid from the isolated rat liver $15 \mathrm{~min}$ after isolation and 15, 30, 45, and $60 \mathrm{~min}$ after $\mathrm{MeOH}(120 \mathrm{mg} / \mathrm{kg})$ injection. ALP, alkaline phosphatase; ALT, alanine aminotransferase; AST, aspartate aminotransferase; ND, not detected, $\mathrm{MeOH}$, methanol.

Table S4 I List of the differentially expressed genes in mice whole brain after ALA treatment. Raw data were quartile normalized and analyzed using the $\mathrm{R}$ language. All the genes included in this table had significant changes in their expression compared to the control, with a $P<0.05$. FC-fold change.

for parkinsonism. Mol. Neurobiol. 9, 149-161. doi: 10.1007/BF028 16115

Chen, C.-H., Budas, G. R., Churchill, E. N., Disatnik, M.-H., Hurley, T. D., and Mochly-Rosen, D. (2008). Activation of aldehyde dehydrogenase2 reduces ischemic damage to the heart. Science 321, 1493-1495. doi: 10.1126/science.1158554

Chen, K., Kazachkov, M., and Yu, P. H. (2007). Effect of aldehydes derived from oxidative deamination and oxidative stress on beta-amyloid aggregation; pathological implications to Alzheimer's disease. J. Neural Transm. 114, 835-839. doi: 10.1007/s00702-007-0697-5

Cloos, P. A. C., Christensen, J., Agger, K., and Helin, K. (2008). Erasing the methyl mark: histone demethylases at the center of cellular differentiation and disease. Genes Dev. 22, 1115-1140. doi: 10.1101/gad.1652908

Constantinescu, A., Pick, U., Handelman, G. J., Haramaki, N., Han, D., Podda, M., et al. (1995). Reduction and transport of lipoic acid by human erythrocytes. Biochem. Pharmacol. 50, 253-261. doi: 10.1016/0006-2952(95) 00084-D

Coon, M. J., and Koop, D. R. (1987). Alcohol-inducible cytochrome P-450 (P450ALC). Arch. Toxicol. 60, 16-21. doi: 10.1007/BF00296940

Cronan, J. E. (2016). Assembly of lipoic acid on its cognate enzymes: an extraordinary and essential biosynthetic pathway. Microbiol. Mol. Biol. Rev. 80, 429-450. doi: 10.1128/MMBR.00073-15

Deng, X., and Deitrich, R. A. (2008). Putative role of brain acetaldehyde in ethanol addiction. Curr. Drug Abuse Rev. 1, 3-8. doi: 10.2174/1874473710801010003

Dong, K., Hao, P., Xu, S., Liu, S., Zhou, W., Yue, X., et al. (2017). Alphalipoic acid alleviates high-glucose suppressed osteogenic differentiation of MC3T3-E1 cells via antioxidant effect and PI3K/Akt signaling pathway. Cell. Physiol. Biochem. Int. J. Exp. Cell. Physiol. Biochem. Pharmacol. 42, 1897-1906. doi: $10.1159 / 000479605$ 
Dorokhov, Y. L., Komarova, T. V., Petrunia, I. V., Kosorukov, V. S., Zinovkin, R. A., Shindyapina, A. V., et al. (2012). Methanol may function as a cross-kingdom signal. PLoS ONE 7:e36122. doi: 10.1371/journal.pone.0036122

Dorokhov, Y. L., Shindyapina, A. V., Sheshukova, E. V., and Komarova, T. V. (2015). Metabolic methanol: molecular pathways and physiological roles. Physiol. Rev. 95, 603-644. doi: 10.1152/physrev.00034.2014

Doser, T. A., Turdi, S., Thomas, D. P., Epstein, P. N., Li, S.-Y., and Ren, J. (2009). Transgenic overexpression of aldehyde dehydrogenase-2 rescues chronic alcohol intake-induced myocardial hypertrophy and contractile dysfunction. Circulation 119, 1941-1949. doi: 10.1161/CIRCULATIONAHA.108.823799

Dudek, M., Knutelska, J., Bednarski, M., Nowinski, L., Zygmunt, M., BilskaWilkosz, A., et al. (2014). Alpha lipoic acid protects the heart against myocardial post ischemia-reperfusion arrhythmias via KATP channel activation in isolated rat hearts. Pharmacol. Rep. 66, 499-504. doi: 10.1016/j.pharep.2013.11.001

Edenberg, H. J., and Foroud, T. (2013). Genetics and alcoholism. Nat. Rev. Gastroenterol. Hepatol. 10, 487-494. doi: 10.1038/nrgastro,.2013.86

ENCODE Project Consortium, Birney, E., Stamatoyannopoulos, J. A., Dutta, A., Guigó, R., Gingeras, T. R., et al. (2007). Identification and analysis of functional elements in $1 \%$ of the human genome by the ENCODE pilot project. Nature 447, 799-816. doi: 10.1038/nature05874

Fujita, H., Shiosaka, M., Ogino, T., Okimura, Y., Utsumi, T., Sato, E. F., et al. (2008). Alpha-lipoic acid suppresses 6-hydroxydopamine-induced ROS generation and apoptosis through the stimulation of glutathione synthesis but not by the expression of heme oxygenase-1. Brain Res. 1206, 1-12. doi: 10.1016/j.brainres.2008.01.081

Galter, D., Carmine, A., Buervenich, S., Duester, G., and Olson, L. (2003). Distribution of class I, III and IV alcohol dehydrogenase mRNAs in the adult rat, mouse and human brain. Eur. J. Biochem. FEBS 270, 1316-1326. doi: 10.1046/j.1432-1033.2003.03502.x

Halliwell, B. (2006). Reactive species and antioxidants. redox biology is a fundamental theme of aerobic life. Plant Physiol. 141, 312-322. doi: 10.1104/pp.106.077073

Han, D., Handelman, G., Marcocci, L., Sen, C. K., Roy, S., Kobuchi, H., et al. (1997). Lipoic acid increases de novo synthesis of cellular glutathione by improving cystine utilization. BioFactors Oxf. Engl. 6, 321-338. doi: $10.1002 /$ biof. 5520060303

He, L., Liu, B., Dai, Z., Zhang, H.-F., Zhang, Y.-S., Luo, X.-J., et al. (2012). Alpha lipoic acid protects heart against myocardial ischemia-reperfusion injury through a mechanism involving aldehyde dehydrogenase 2 activation. Eur. J. Pharmacol. 678, 32-38. doi: 10.1016/j.jphar.2011.12.042

Hiltunen, J. K., Autio, K. J., Schonauer, M. S., Kursu, V. A. S., Dieckmann, C. L., and Kastaniotis, A. J. (2010). Mitochondrial fatty acid synthesis and respiration. Biochim. Biophys. Acta 1797, 1195-1202. doi: 10.1016/j.bbabio.2010.03.006

Hou, H., and Yu, H. (2010). Structural insights into histone lysine demethylation. Curr. Opin. Struct. Biol. 20, 739-748. doi: 10.1016/j.sbi.2010.09.006

Hume, M. A., Barrera, L. A., Gisselbrecht, S. S., and Bulyk, M. L. (2015). UniPROBE, update 2015: new tools and content for the online database of protein-binding microarray data on protein-DNA interactions. Nucleic Acids Res. 43, D117-D122. doi: 10.1093/nar/gku1045

Ishikawa, H., Ishikawa, T., Yamamoto, H., Fukao, A., and Yokoyama, K. (2007). Genotoxic effects of alcohol in human peripheral lymphocytes modulated by ADH1B and ALDH2 gene polymorphisms. Mutat. Res. 615, 134-142. doi: 10.1016/j.mrfmmm.2006.11.026

Julià, P., Farrés, J., and Parés, X. (1987). Characterization of three isoenzymes of rat alcohol dehydrogenase. Tissue distribution and physical and enzymatic properties. Eur. J. Biochem. FEBS 162, 179-189. doi: 10.1111/j.1432-1033.1987.tb10559.x

Kamarudin, M. N. A., Mohd Raflee, N. A., Hussein, S. S. S., Lo, J. Y., Supriady, H., and Abdul Kadir, H. (2014). (R)-(+)- $\alpha$-lipoic acid protected NG108-15 cells against $\mathrm{H} 2 \mathrm{O} 2$-induced cell death through PI3K-Akt/GSK-3 $\beta$ pathway and suppression of NF-к $\beta$-cytokines. Drug Des. Dev. Ther. 8, 1765-1780. doi: 10.2147/DDDT.S67980

Kimura, Y., Nishimura, F. T., Abe, S., Fukunaga, T., Tanii, H., and Saijoh, K. (2009). A promoter polymorphism in the ALDH2 gene affects its basal and acetaldehyde/ethanol-induced gene expression in human peripheral blood leukocytes and HepG2 cells. Alcohol Alcohol. 44, 261-266. doi: $10.1093 /$ alcalc/agn123
Komarova, T. V., Petrunia, I. V., Shindyapina, A. V., Silachev, D. N., Sheshukova, E. V., Kiryanov, G. I., et al. (2014). Endogenous methanol regulates mammalian gene activity. PLoS ONE 9:e90239. doi: 10.1371/journal.pone.0090239

Lee, E.-S., Chen, H., Hardman, C., Simm, A., and Charlton, C. (2008). Excessive S-adenosyl-L-methionine-dependent methylation increases levels of methanol, formaldehyde and formic acid in rat brain striatal homogenates: possible role in S-adenosyl-L-methionine-induced Parkinson's disease-like disorders. Life Sci. 83, 821-827. doi: 10.1016/j.lfs.2008.09.020

Li, J.-H., Ju, G.-X., Jiang, J.-L., Li, N.-S., Peng, J., and Luo, X.-J. (2016a). Lipoic acid protects gastric mucosa from ethanol-induced injury in rat through a mechanism involving aldehyde dehydrogenase 2 activation. Alcohol 56, 21-28. doi: 10.1016/j.alcohol.2016.10.004

Li, R.-J., Ji, W.-Q., Pang, J.-J., Wang, J.-L., Chen, Y.-G., and Zhang, Y. (2013). Alpha-lipoic acid ameliorates oxidative stress by increasing aldehyde dehydrogenase-2 activity in patients with acute coronary syndrome. Tohoku J. Exp. Med. 229, 45-51. doi: 10.1620/tjem.229.45

Li, T., Su, T., He, Y., Lu, J., Mo, W., Wei, Y., et al. (2016b). Brain formaldehyde is related to water intake behavior. Aging Dis. 7, 561-584. doi: 10.14336/AD.2016.0323

Liu, J., Liu, F.-Y., Tong, Z.-Q., Li, Z.-H., Chen, W., Luo, W.-H., et al. (2013). Lysinespecific demethylase 1 in breast cancer cells contributes to the production of endogenous formaldehyde in the metastatic bone cancer pain model of rats. PLoS ONE 8:e58957. doi: 10.1371/journal.pone.0058957

Lv, C., Wu, C., Zhou, Y., Shao, Y., Wang, G., and Wang, Q. (2014). Alpha lipoic acid modulated high glucose-induced rat mesangial cell dysfunction via $\mathrm{mTOR} / \mathrm{p} 70 \mathrm{~S} 6 \mathrm{~K} / 4 \mathrm{E}-\mathrm{BP} 1$ Pathway. Int. J. Endocrinol. 2014:658589. doi: $10.1155 / 2014 / 658589$

Ma, R., Wang, X., Peng, P., Xiong, J., Dong, H., Wang, L., et al. (2016). $\alpha$-lipoic acid inhibits sevoflurane-induced neuronal apoptosis through PI3K/Akt signalling pathway. Cell Biochem. Funct. 34, 42-47. doi: 10.1002/cbf.3163

Macias-Barragan, J., Huerta-Olvera, S. G., Hernandez-Cañaveral, I., Pereira-Suarez, A. L., and Montoya-Buelna, M. (2017). Cadmium and $\alpha$-lipoic acid activate similar de novo synthesis and recycling pathways for glutathione balance. Environ. Toxicol. Pharmacol. 52, 38-46. doi: 10.1016/j.etap.2017.03.007

Mayr, J. A., Feichtinger, R. G., Tort, F., Ribes, A., and Sperl, W. (2014). Lipoic acid biosynthesis defects. J. Inherit. Metab. Dis. 37, 553-563. doi: $10.1007 /$ s10545-014-9705-8

McCarty, M. F. (2013). Nutraceutical strategies for ameliorating the toxic effects of alcohol. Med. Hypotheses 80, 456-462. doi: 10.1016/j.mehy.2012.12.040

Moura, F. A., de Andrade, K. Q., dos Santos, J. C. F., and Goulart, M. O. F. (2015). Lipoic acid: its antioxidant and anti-inflammatory role and clinical applications. Curr. Top. Med. Chem. 15, 458-483. doi: $10.2174 / 1568026615666150114161358$

Muñoz-Clares, R. A., González-Segura, L., Murillo-Melo, D. S., and RiverosRosas, H. (2017). Mechanisms of protection against irreversible oxidation of the catalytic cysteine of ALDH enzymes: possible role of vicinal cysteines. Chem. Biol. Interact. 276, 52-64. doi: 10.1016/j.cbi.2017.02.007

Ou, P., Tritschler, H. J., and Wolff, S. P. (1995). Thioctic (lipoic) acid: a therapeutic metal-chelating antioxidant? Biochem. Pharmacol. 50, 123-126. doi: 10.1016/0006-2952(95)00116-H

Packer, L., Witt, E. H., and Tritschler, H. J. (1995). Alpha-lipoic acid as a biological antioxidant. Free Radic. Biol. Med. 19, 227-250. doi: 10.1016/0891-5849(95)00017-R

Panigrahi, M., Sadguna, Y., Shivakumar, B. R., Kolluri, S. V., Roy, S., Packer, L., et al. (1996). Alpha-lipoic acid protects against reperfusion injury following cerebral ischemia in rats. Brain Res. 717, 184-188. doi: 10.1016/0006-8993(96)00009-1

Perez-Miller, S., Younus, H., Vanam, R., Chen, C.-H., Mochly-Rosen, D., and Hurley, T. D. (2010). Alda-1 is an agonist and chemical chaperone for the common human aldehyde dehydrogenase 2 variant. Nat. Struct. Mol. Biol. 17, 159-164. doi: 10.1038/nsmb.1737

Pfaffl, M. W. (2001). A new mathematical model for relative quantification in real-time RT -PCR. Nucleic Acids Res. 29:e45.

Podda, M., Tritschler, H. J., Ulrich, H., and Packer, L. (1994). Alpha-lipoic acid supplementation prevents symptoms of vitamin E deficiency. Biochem. Biophys. Res. Commun. 204, 98-104. doi: 10.1006/bbrc.1994.2431 
Prasad, K. N. (2016). Simultaneous activation of Nrf2 and elevation of antioxidant compounds for reducing oxidative stress and chronic inflammation in human Alzheimer's disease. Mech. Ageing Dev. 153, 41-47. doi: 10.1016/j.mad.2016.01.002

Rosenberg, H. R., and Culik, R. (1959). Effect of $\alpha$-lipoic acid on vitamin $\mathrm{C}$ and vitamin E deficiencies. Arch. Biochem. Biophys. 80, 86-93. doi: 10.1016/0003-9861(59)90345-5

Sen, C. K., Roy, S., Han, D., and Packer, L. (1997). Regulation of cellular thiols in human lymphocytes by alpha-lipoic acid: a flow cytometric analysis. Free Radic. Biol. Med. 22, 1241-1257. doi: 10.1016/S0891-5849(96)00552-7

Shay, K. P., Moreau, R. F., Smith, E. J., Smith, A. R., and Hagen, T. M. (2009). Alpha-lipoic acid as a dietary supplement: molecular mechanisms and therapeutic potential. Biochim. Biophys. Acta 1790, 1149-1160. doi: 10.1016/j.bbagen.2009.07.026

Shi, C., Zhou, X., Zhang, J., Wang, J., Xie, H., and Wu, Z. (2016). $\alpha$-lipoic acid protects against the cytotoxicity and oxidative stress induced by cadmium in HepG2 cells through regeneration of glutathione by glutathione reductase via Nrf2/ARE signaling pathway. Environ. Toxicol. Pharmacol. 45, 274-281. doi: 10.1016/j.etap.2016.06.003

Shindyapina, A. V., Petrunia, I. V., Komarova, T. V., Sheshukova, E. V., Kosorukov, V. S., Kiryanov, G. I., et al. (2014). Dietary methanol regulates human gene activity. PLoS ONE 9:e102837. doi: 10.1371/journal.pone.0102837

Sládek, N. E. (2003). Human aldehyde dehydrogenases: potential pathological, pharmacological, and toxicological impact. J. Biochem. Mol. Toxicol. 17, 7-23. doi: 10.1002/jbt.10057

Sophos, N. A., and Vasiliou, V. (2003). Aldehyde dehydrogenase gene superfamily: the 2002 update. Chem. Biol. Interact. 143-144, 5-22. doi: 10.1016/S0009-2797(02)00163-1

Su, T., Monte, W. C., Hu, X., He, Y., and He, R. (2016). Formaldehyde as a trigger for protein aggregation and potential target for mitigation of agerelated, progressive cognitive impairment. Curr. Top. Med. Chem. 16, 472-484. doi: 10.2174/1568026615666150813142215

Suh, J. H., Shenvi, S. V., Dixon, B. M., Liu, H., Jaiswal, A. K., Liu, R.-M., et al. (2004). Decline in transcriptional activity of Nrf2 causes age-related loss of glutathione synthesis, which is reversible with lipoic acid. Proc. Natl. Acad. Sci. U.S.A. 101, 3381-3386. doi: 10.1073/pnas.0400282101

Tang, X., Bai, Y., Duong, A., Smith, M. T., Li, L., and Zhang, L. (2009). Formaldehyde in China: production, consumption, exposure levels, and health effects. Environ. Int. 35, 1210-1224. doi: 10.1016/j.envint.2009.06.002

Tang, X.-Q., Fang, H.-R., Zhou, C.-F., Zhuang, Y.-Y., Zhang, P., Gu, H.-F., et al. (2013a). A novel mechanism of formaldehyde neurotoxicity: inhibition of hydrogen sulfide generation by promoting overproduction of nitric oxide. PLoS ONE 8:e54829. doi: 10.1371/journal.pone.0054829

Tang, X.-Q., Zhuang, Y.-Y., Zhang, P., Fang, H.-R., Zhou, C.-F., Gu, H.-F., et al. (2013b). Formaldehyde impairs learning and memory involving the disturbance of hydrogen sulfide generation in the hippocampus of rats. J. Mol. Neurosci. 49, 140-149. doi: 10.1007/s12031-012-9912-4

Tong, Z., Han, C., Luo, W., Li, H., Luo, H., Qiang, M., et al. (2013a). Agingassociated excess formaldehyde leads to spatial memory deficits. Sci. Rep. 3:1807. doi: 10.1038/srep01807

Tong, Z., Han, C., Luo, W., Wang, X., Li, H., Luo, H., et al. (2013b). Accumulated hippocampal formaldehyde induces age-dependent memory decline. Age 35, 583-596. doi: 10.1007/s11357-012-9388-8
Tong, Z., Wang, W., Luo, W., Lv, J., Li, H., Luo, H., et al. (2017). Urine formaldehyde predicts cognitive impairment in post-stroke dementia and Alzheimer's disease. J. Alzheimers Dis. 55, 1031-1038. doi: 10.3233/JAD160357

Tong, Z., Zhang, J., Luo, W., Wang, W., Li, F., Li, H., et al. (2011). Urine formaldehyde level is inversely correlated to mini mental state examination scores in senile dementia. Neurobiol. Aging 32, 31-41. doi: 10.1016/j.neurobiolaging.2009.07.013

Tsukada, Y., Fang, J., Erdjument-Bromage, H., Warren, M. E., Borchers, C. H., Tempst, P., et al. (2006). Histone demethylation by a family of JmjC domaincontaining proteins. Nature 439, 811-816. doi: 10.1038/nature04433

Tulpule, K., and Dringen, R. (2013). Formaldehyde in brain: an overlooked player in neurodegeneration? J. Neurochem. 127, 7-21. doi: 10.1111/jnc. 12356

Tulpule, K., Hohnholt, M. C., and Dringen, R. (2013). Formaldehyde metabolism and formaldehyde-induced stimulation of lactate production and glutathione export in cultured neurons. J. Neurochem. 125, 260-272. doi: 10.1111/jnc.12170

Venigalla, M., Sonego, S., Gyengesi, E., Sharman, M. J., and Münch, G. (2016). Novel promising therapeutics against chronic neuroinflammation and neurodegeneration in Alzheimer's disease. Neurochem. Int. 95, 63-74. doi: 10.1016/j.neuint.2015.10.011

Wallage, H. R., and Watterson, J. H. (2008). Formic acid and methanol concentrations in death investigations. J. Anal. Toxicol. 32, 241-247. doi: $10.1093 /$ jat/32.3.241

Walport, L. J., Hopkinson, R. J., and Schofield, C. J. (2012). Mechanisms of human histone and nucleic acid demethylases. Curr. Opin. Chem. Biol. 16, 525-534. doi: 10.1016/j.cbpa.2012.09.015

Wang, J.-C., Kapoor, M., and Goate, A. M. (2012). The genetics of substance dependence. Annu. Rev. Genomics Hum. Genet. 13, 241-261. doi: 10.1146/annurev-genom-090711-163844

Ziegler, D., Hanefeld, M., Ruhnau, K. J., Hasche, H., Lobisch, M., Schütte, K., et al. (1999). Treatment of symptomatic diabetic polyneuropathy with the antioxidant alpha-lipoic acid: a 7-month multicenter randomized controlled trial (ALADIN III Study). ALADIN III study group. alphalipoic acid in diabetic neuropathy. Diabetes Care 22, 1296-1301. doi: $10.2337 /$ diacare.22.8.1296

Ziegler, D., Hanefeld, M., Ruhnau, K. J., Meissner, H. P., Lobisch, M., Schütte, K., et al. (1995). Treatment of symptomatic diabetic peripheral neuropathy with the anti-oxidant alpha-lipoic acid. A 3-week multicentre randomized controlled trial (ALADIN Study). Diabetologia 38, 1425-1433. doi: 10.1007/BF00400603

Conflict of Interest Statement: The authors declare that the research was conducted in the absence of any commercial or financial relationships that could be construed as a potential conflict of interest.

Copyright (C) 2017 Shindyapina, Komarova, Sheshukova, Ershova, Tashlitsky, Kurkin, Yusupov, Mkrtchyan, Shagidulin and Dorokhov. This is an open-access article distributed under the terms of the Creative Commons Attribution License (CC $B Y)$. The use, distribution or reproduction in other forums is permitted, provided the original author(s) or licensor are credited and that the original publication in this journal is cited, in accordance with accepted academic practice. No use, distribution or reproduction is permitted which does not comply with these terms. 